\title{
Viscoelasticity of periodontal ligament: an analytical model
}

\author{
Sergei M. Bosiakov* (1), Anna A. Koroleva², Sergei V. Rogosin³ and Vadim V. Silberschmidt ${ }^{4}$
}

\begin{abstract}
Background: Understanding of viscoelastic behaviour of a periodontal membrane under physiological conditions is important for many orthodontic problems. A new analytic model of a nearly incompressible viscoelastic periodontal ligament is suggested, employing symmetrical paraboloids to describe its internal and external surfaces.

Methods: In the model, a tooth root is assumed to be a rigid body, with perfect bonding between its external surface and an internal surface of the ligament. An assumption of almost incompressible material is used to formulate kinematic relationships for a periodontal ligament; a viscoelastic constitutive equation with a fractional exponential kernel is suggested for its description.

Results: Translational and rotational equations of motion are derived for ligament's points and special cases of translational displacements of the tooth root are analysed. Material parameters of the fractional viscoelastic function are assessed on the basis of experimental data for response of the periodontal ligament to tooth translation. A character of distribution of hydrostatic stresses in the ligament caused by vertical and horizontal translations of the tooth root is defined.

Conclusions: The proposed model allows generalization of the known analytical models of the viscoelastic periodontal ligament by introduction of instantaneous and relaxed elastic moduli, as well as the fractional parameter. The latter makes it possible to take into account different behaviours of the periodontal tissue under short- and long-term loads. The obtained results can be used to determine loads required for orthodontic tooth movements corresponding to optimal stresses, as well as to simulate bone remodelling on the basis of changes in stresses and strains in the periodontal ligament caused by such movements.
\end{abstract}

Keywords: Periodontal ligament, Tooth root, Viscoelastic model, Fractional exponential function, Translational displacement

\section{Background}

A root of a tooth is attached to an alveolar bone by a periodontal ligament (PDL), a soft connective tissue consisting of collagen fibres and a matrix phase with nerve endings and blood vessels (Bergomi et al. 2011; Berkovitz et al. 1995; Chatterjee 2006; Chiba 2004; Fill et al. 2011; Nanci and Ten Cate AR 2008; Natali 2003; Nishihira et al. 2003). In addition to providing interconnection for a tooth with its supporting structures, the PDL responds to applied loads, demonstrating viscoelastic time-dependent properties (Burstone et al. 1978; Jonsdottir et al. 2006;

\footnotetext{
*Correspondence: bosiakov@bsu.by

${ }^{1}$ Department of Mechanics and Mathematics, Belarusian State University, 4, Nezavisimosti Avenue, 220030 Minsk, Belarus

Full list of author information is available at the end of the article
}

Komatsu 2010; Komatsu et al. 2007; Middleton et al. 1996; Picton 1990; Qian et al. 2009; Ross et al. 1976; Toms and Eberhardt 2003).

Depending on duration of the applied load, initial and orthodontic tooth motions are distinguished (Dorow et al. 2003; Frost 1992; Kawarizadeh et al. 2003; Middleton et al. 1996). The former occurs under a shortterm load, with the tooth returning to its original position after load removal (Muhlemann and Zander 1954; Tanne et al. 1991; Ziegler et al. 2005), accompanied by a rearrangement of bone tissue. Thus, the PDL plays an important role in ensuring a proper reaction of bone. Analysis of biological mechanisms underpinning tooth movements (Davidovitch and Shanfeld 1975; Proffit et al. 1993; Reitan and Rygh 1994) showed that stresses and

\section{黛 Springer}

(c) 2015 Bosiakov et al. Open Access This article is distributed under the terms of the Creative Commons Attribution 4.0 International License (http://creativecommons.org/licenses/by/4.0/), which permits unrestricted use, distribution, and reproduction in any medium, provided you give appropriate credit to the original author(s) and the source, provide a link to the Creative Commons license, and indicate if changes were made. 
strains in the PDL, caused by external forces, were a key driver of bone reconstruction. Stretching and compression the PDL tissue lead to resorption and bone formation, respectively (Bourauel et al. 2000; Davidovitch et al. 1980; Masella and Meister 2006; Melsen 2001; Roberts and Chase 1981; Storey 1973; Wise and King 2008).

Short- and long-term (orthodontic) teeth motions can be modelled employing a linear elastic, bilinear elastic, viscoelastic, hyperelastic, or multiphase formulation for the PDL Bergomi et al. 2011; Cattaneo et al. 2005; Ferrari et al. 2008; Fill et al. 2012; Kawarizadeh et al. 2003; Middleton et al. 1996; Muraki et al. 2004; Natali et al. 2002; Natali et al. 2011; Provatidis 2000, Qian et al. 2009). The same type of continuous models are used to calculate stress-strain states of the PDL for various load types, as implemented in different finite-element studies (Cattaneo et al. 2005; Clement et al. 2004; Dorow and Sander 2005; Ferrari et al. 2008; Hohmann et al. 2011; Jeon et al. 1999; Jones et al. 2001; Kawarizadeh et al. 2003; Muraki et al. 2004; Natali et al. 2004; Pietrzak et al. 2002, Provatidis 2000; Qian et al. 2009; Reimann et al. 2009; Toms and Eberhardt 2003; Vollmer et al. 1999, Ziegler et al. 2005). Because of their complexity, analytical modelling of elastic and viscoelastic responses of PDLs to loads applied to the tooth was carried out in a relatively small number of studies (Kusy and Tulloch 1986; Natali et al. 2007; Nikolai 1996; Pena et al. 2007, 2008a,b; Provatidis 2001; Slomka et al. 2008; Smith and Burstone 1984; Van Schepdael et al. 2013). Most important results for 3-D cases were obtained using circular and ellipticparaboloid shapes for the tooth root and PDL surfaces (Haack and Haft 1972; Provatidis 2001; Van Schepdael et al. 2013). In addition, results of a study by Bourauel et al. (2000) demonstrated that approximation of the actual geometry of the tooth with a paraboloid having an elliptical cross-section allows modelling the short-term and orthodontic tooth movements with high accuracy. In studies of Provatidis (2001), Van Schepdael et al. (2013), models a tooth root and a PDL in the form of a paraboloid were used to identify the magnitudes of initial displacements under static loads, stress-strain states of the PDL, a position of the centre of resistance of the tooth, as well as the effect of eccentricity of a cross section at initial displacements. An important feature of the used analytical model was an approximation of the PDL as an almost incompressible material with a Poisson's ratio equal to 0.4-0.49 (Rees and Jacobsen 1997). In this case, it can be assumed that maximum deformation of the PDL tissue along a normal to the tooth-root surface coincides with thickness of the PDL in the same direction. Finiteelement studies of the PDL's stress-strain state under instantaneous loads (corresponding to small displacements of the tooth root) indicated high accuracy of the analytical model. A further development of the analytical scheme for the almost incompressible PDL proposed by Provatidis (2001) can be implemented for long-term and heavy loads, taking into account time-dependent and viscoelastic properties of the PDL.

The aim of our study is to develop an analytical model of a viscoelastic PDL with a fractional exponential kernel to describe evolution of deformation in a periodontal tissue and evaluate tooth-root movements with time. Viscoelastic behaviour of the periodontal ligament is in agreement with the widely employed Nutting law (Koeller 1984; 2010; Mainardi 2010; Uchaikin 2013) that can be simply presented in the form of the dependence of the shear stress using of strain and time. Such a relationship is suitable when the material properties are determined by various states between an elastic body and a viscous fluid.

\section{Methods}

\section{Geometrical form of tooth root and PDL}

In the suggested approach, an external surface of a tooth root (supposed to be a rigid body) and an adjacent inner surface of the PDL are modelled with a paraboloid (Van Schepdael et al. 2013)

$$
F(x, y, z)=\frac{y}{h}-\frac{1}{b^{2}}\left(\left(1-e^{2}\right) x^{2}+z^{2}\right)=0,
$$

where $h$ is the height of the tooth root; $e=\sqrt{1-(b / a)^{2}}$ is the eccentricity of the elliptical cross-section of the tooth in the alveolar crest; $a$ and $b$ are the semi-axes of this ellipse.

The internal surface of the PDL adjacent to the dental alveolar bone is shifted along the normal to the surface of the tooth root. Its equation is as follows:

$$
\begin{aligned}
F_{1}(x, y, z)= & \frac{y+n_{y} \delta}{h}-\frac{1}{b^{2}}\left(\left(1-e^{2}\right)\left(x+n_{x} \delta\right)^{2}\right. \\
& \left.+\left(z+n_{z} \delta\right)^{2}\right)=0,
\end{aligned}
$$

where $n_{x}, n_{y}$, and $n_{z}$ are the components of the unit normal vector to the surface of the first paraboloid; $\delta>0$. The components of the normal vector are determined from (1):

$$
\begin{aligned}
& n_{x}=-\frac{2\left(1-e^{2}\right) h x}{b^{2} \Delta}, n_{y}=\frac{1}{\Delta}, n_{z}=-\frac{2 h z}{b^{2} \Delta}, \\
& \Delta=\frac{1}{b^{2}} \sqrt{b^{4}+4 h^{2}\left(\left(1-e^{2}\right)^{2} x^{2}+z^{2}\right)} .
\end{aligned}
$$

Under a concentrated force, points of the PDL on the tooth-root surface (1) begin to move with the root, while the external surface of the PDL is fixed. There is no significant difference between the schemes considering fixing of the outer surface of the PDL to the alveolar bone or its full constraint. Hence, to calculate the initial movement of the teeth in the PDL, both the 
teeth and the alveolar bone could be considered as solids (Hohmann et al. 2011).

\section{Expressions for strains and displacements}

Following Kawarizadeh et al. (2003), Rees and Jacobsen (1997), it is supposed that the PDL has a Poisson's ratio equal to 0.49 , i.e. effectively incompressible. This means that it should exhibit a fluid-like behaviour, flowing around the surface of the root of the tooth when the latter is displaced to the wall of the dental alveolar bone (Kawarizadeh et al. 2003). Hence, strains and relative shears associated with a normal vector, a generatrix of, and a tangent to, the external surface of the tooth root could be represented in the coordinate system as follows (Provatidis 2001; Van Schepdael et al. 2013):

$$
\varepsilon_{n n}=-\frac{u_{n}}{\delta}, \varepsilon_{t t}=\varepsilon_{\theta \theta}=0, \gamma_{n \theta}=-\frac{u_{\theta}}{\delta}, \gamma_{n t}=-\frac{u_{t}}{\delta}, \gamma_{t \theta}=0
$$

where $u_{n}, u_{\theta}$ and $u_{t}$ are displacements of the PDL points, with subscripts $n, \theta$ and $t$, denoting the normal, tangential directions with regard to the root surface, and the generatrix of it, and $\delta$ being the thickness of the PDL in the normal direction. The normal vector $\vec{n}$, tangential $\vec{\theta}$ to the root surface of the tooth and generatrix $\vec{t}$, as well as its geometrical dimensions are shown in Fig. 1.

Any displacements of the rigid tooth root can be presented as a combination of translational displacements $u_{0 x}, u_{0 y}, u_{0 z}$ and angles of rotation $\theta_{x}, \theta_{y}, \theta_{z}$ with regard to the axes of coordinates. Since the thickness of PDL is small, the rotation angles are small, too. Hence, the following linearized expressions can be used:

$$
\begin{aligned}
& u_{x}=u_{0 x}+z \theta_{y}-y \theta_{z}, u_{y}=u_{0 y}-z \theta_{x}+x \theta_{z}, \\
& u_{z}=u_{0 z}+y \theta_{x}-x \theta_{y} .
\end{aligned}
$$

After transformation in accordance with Van Schepdael et al. (2013), the relationships between the displacements $u_{x}, u_{y}$ and $u_{z}$ of the tooth root and strains in the PDL $\varepsilon_{x x}, \varepsilon_{y y}, \varepsilon_{z z}, \gamma_{x y}, \gamma_{y z}$ and $\gamma_{x z}$ can be obtained in Cartesian coordinates.

\section{Constitutive equations}

An overview of specific applications of different models of PDL is given in (Fill et al. 2012). The main drawback of schemes presenting a PDL in simulations as a material with a complex mechanical behaviour is a lack of accurate quantitative data for respective mechanical parameters. For viscoelastic models it is compensated by availability of known magnitudes of relaxation times and elasticity moduli (Komatsu 2010; Qian et al. 2009; Wood et al. 2011), and experimentally determined viscoelastic properties (Bergomi et al. 2011; Ferrari et al. 2008; Natali 2003;

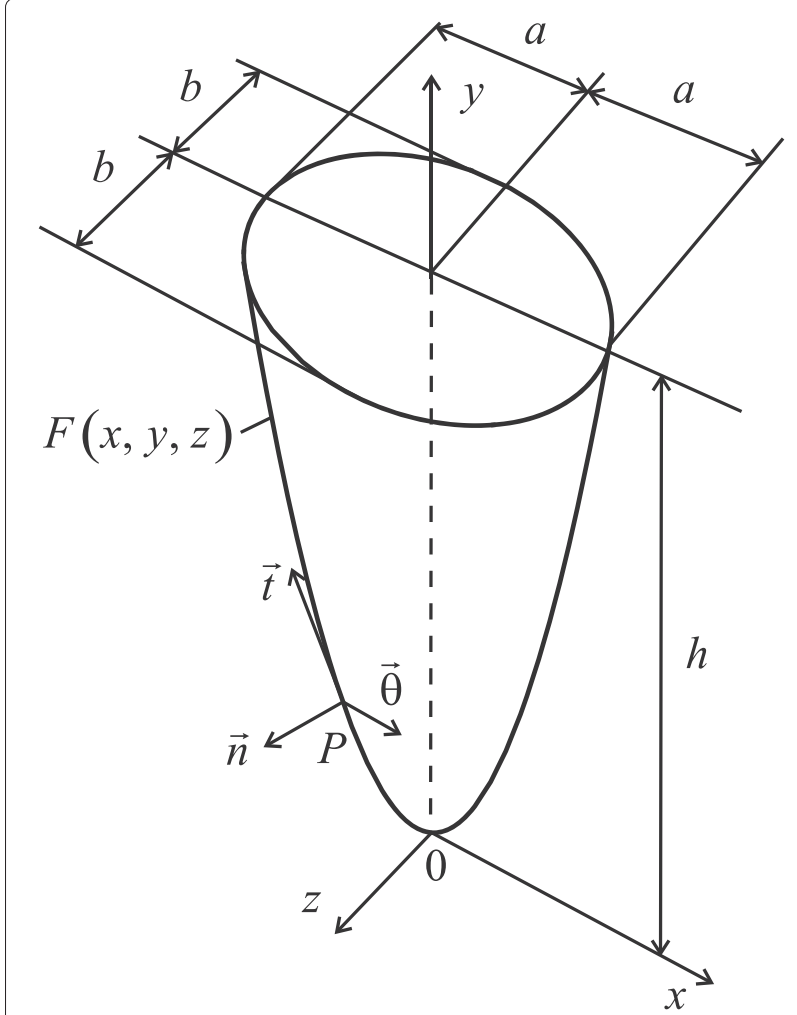

Fig. 1 Geometrical shape of tooth root: $\vec{n}$ is normal, $\vec{t}$ is generatrix, $\vec{\theta}$ is tangential to surface of tooth root in point $P$

Naveh et al. 2012; Toms and Eberhardt 2003; Toms et al. 2002; Yoshida et al. 2001).

Several models of viscoelastic behaviour of the PDL, based on approaches by Maxwell, Voigt and, Kelvin-Voigt, were proposed (Fill et al. 2012). Such material are said to exhibit a rheological behaviour. Rheology as a branch of science is concerned with extending continuum mechanics to characterization of flow of materials, with a combination of elastic, viscous and plastic properties by merging elasticity and (Newtonian) fluid mechanics. In particular, materials studied within the framework of rheology could have a memory (so called hereditary materials). To model this effect, a fractional calculus can be used, e.g., (Koeller 2010; Uchaikin 2013; West et al. 2003); the history of fractional modelling in rheology is presented in (Rogosin and Mainardi 2014) (see also (Mainardi 2010) and references therein). A fractional viscoelastic model provides a rather natural approach for a study of periodontal membranes. In addition, fractional models (i.e. models with fractional derivatives) are successfully used to solve different problems of mechanics (Rossikhin and Shitikova 2013b; Rossikhin et al. 2014).

A general theory of mechanics of hereditary materials was suggested by Rabotnov (1980) using integral equations; Koeller (1984) reviewed the application 
of integral equations to viscoelasticity and introduced fractional calculus into the Rabotnov's theory employing a structural spring-dashpot model, used to generalize the classical mechanical models. Rossikhin and Shitikova (2015) summarized the Rabotnov's theory (see also (Rossikhin and Shitikova 2014)). The Rabotnov's fractional exponential function is related to a well-known Mittag-Leffler function (Gorenflo et al. 2014). Using this relation, it can be shown that the Rabotnov's theory is equivalent to the scheme by Torvik and Bagley based on a fractional polynomial constitutive equation. Thus, a viscoelastic model with a fractional exponential kernel is highly suitable for modelling of mechanical behaviour of biological materials with time-dependent properties. In a viscoelastic scheme similar to the Rabotnov's model, components of a stress tensor can be presented in the following form, taking into account viscoelastic properties of the PDL:

$$
\begin{aligned}
\sigma_{i j}= & \frac{E_{\infty}}{(1-2 v)(1+v)}\left\{(1-2 v) \varepsilon_{i j}-v_{\varepsilon} \int_{0}^{t} \mathcal{E}_{\gamma}\left(-\frac{\tau}{\tau_{\varepsilon}}\right) \varepsilon_{i j}(t-\tau) d \tau+\right. \\
& \left.+v\left(\sum_{k=1}^{3} \varepsilon_{k k}-v_{\varepsilon} \int_{0}^{t} \mathcal{E}_{\gamma}\left(-\frac{\tau}{\tau_{\varepsilon}}\right) \sum_{k=1}^{3} \varepsilon_{k k}(t-\tau) d \tau\right)\right\}
\end{aligned}
$$

where $\tau_{s}$ is the relaxation time; $v_{\varepsilon}=\frac{E_{\infty}-E_{0}}{E_{\infty}}, E_{0}$ and $E_{\infty}$ are, respectively, the instantaneous (glassy) and relaxed (rubbery) elastic moduli (Rossikhin and Shitikova 2015); and $\mathcal{E}_{\gamma}\left(-\frac{\tau}{\tau_{\varepsilon}}\right)$ is the Rabotnov's fractional exponential function, which describes the relaxation of volume and shear stresses. It was introduced by Rabotnov in the following form (Rabotnov 1948; 1980):

$$
\mathcal{E}_{\gamma}\left(-\frac{t}{\tau_{\varepsilon}}\right)=\frac{t^{\gamma-1}}{\tau_{\varepsilon}^{\gamma}} \sum_{n=0}^{\infty}(-1)^{n} \frac{\left(t / \tau_{\varepsilon}\right)^{\gamma n}}{\Gamma[\gamma(n+1)]},
$$

where $0<\gamma<1$ is the fractional parameter. Note that the Rabotnov's function is a special case of the classical Mittag-Leffler function widely used in fractional models (see (Gorenflo et al. 2014; Mainardi 2010)).

\section{Equations of motion}

To find the translational displacements and rotation angles in the PDL, the following conditions of the dynamic equilibrium of the tooth root are used:

$$
\begin{aligned}
& \iint_{F}(\vec{n} \cdot \sigma) d F+M \frac{d^{2} \vec{u}_{0}}{d t^{2}}-\vec{f}=0, \\
& \iint_{F} \vec{r} \times(\vec{n} \cdot \sigma) d F+J \frac{d^{2} \vec{\theta}}{d t^{2}}-\vec{m}=0,
\end{aligned}
$$

where $\vec{m}=\left(m_{x}, m_{y}, m_{z}\right)$ is the principal moment of external forces; $\vec{f}=\left(f_{x}, f_{y}, f_{z}\right)$ is the principal vector of external forces; $\vec{r}$ is the radius-vector; $\vec{n}=\left(n_{x}, n_{y}, n_{z}\right)$ is the unit normal vector to the surface (1), $\sigma$ is the stress tensor; $M$ and $J$ are the mass and axial moment of inertia of the tooth root, respectively; $\vec{u}_{0}=\left(u_{0 x}, u_{0 y}, u_{0 z}\right)$ is the vector of translational displacements of the tooth root along the axes of coordinates, and $\vec{\theta}=\left(\theta_{x}, \theta_{y}, \theta_{z}\right)$ is the vector of rotation angles of the tooth root with respect to the axes. The components of the displacement vector $\vec{u}_{0}$ and the vector of rotation angles $\vec{\theta}$ are functions of time.

Taking into account relations (2) and (5) one can reduce equations of motion (6) (after some transformations) to the following form:

$$
\begin{aligned}
& a_{11}\left(u_{0 x}-v_{\varepsilon} \int_{0}^{t} \mathcal{E}_{\gamma} u_{0 x}(t-\tau) d \tau\right)+a_{16}\left(\theta_{z}-v_{\varepsilon} \int_{0}^{t} \mathcal{E}_{\gamma} \theta_{z}(t-\tau) d \tau\right)+M \frac{d^{2} u_{0 x}}{d t^{2}}=f_{x}, \\
& a_{22}\left(u_{0 y}-v_{\varepsilon} \int_{0}^{t} \mathcal{E}_{\gamma} u_{0 y}(t-\tau) d \tau\right)+M \frac{d^{2} u_{0 y}}{d t^{2}}=f_{y}, \\
& a_{33}\left(u_{0 z}-v_{\varepsilon} \int_{0}^{t} \mathcal{E}_{\gamma} u_{0 z}(t-\tau) d \tau\right)+a_{34}\left(\theta_{x}-v_{\varepsilon} \int_{0}^{t} \mathcal{E}_{\gamma} \theta_{x}(t-\tau) d \tau\right)+M \frac{d^{2} u_{0 z}}{d t^{2}}=f_{z}, \\
& a_{43}\left(u_{0 z}-v_{\varepsilon} \int_{0}^{t} \mathcal{E}_{\gamma} u_{0 z}(t-\tau) d \tau\right)+a_{44}\left(\theta_{x}-v_{\varepsilon} \int_{0}^{t} \mathcal{E}_{\gamma} \theta_{x}(t-\tau) d \tau\right)+ \\
& +J_{x} \frac{d^{2} \theta_{x}}{d t^{2}}=y_{f} f_{z}-z_{f} f_{y}, \\
& a_{55}\left(\theta_{y}-v_{\varepsilon} \int_{0}^{t} \mathcal{E}_{\gamma} \theta_{y}(t-\tau) d \tau\right)+J_{y} \frac{d^{2} \theta_{y}}{d t^{2}}=z_{f} f_{x}-x_{f} f_{z}, \\
& a_{61}\left(u_{0 x}-v_{\varepsilon} \int_{0}^{t} \mathcal{E}_{\gamma} u_{0 x}(t-\tau) d \tau\right)+a_{66}\left(\theta_{z}-v_{\varepsilon} \int_{0}^{t} \mathcal{E}_{\gamma} \theta_{z}(t-\tau) d \tau\right)+ \\
& +J_{z} \frac{d^{2} \theta_{z}}{d t^{2}}=x_{f} f_{y}-y_{f} f_{x}, \\
& \mathcal{E}_{\gamma} \equiv \mathcal{E}_{\gamma}\left(-\frac{\tau}{\tau_{\varepsilon}}\right),
\end{aligned}
$$

where $x_{f}, y_{f}$ and $z_{f}$ are the coordinates of the point where the load is applied. The coefficients of the system (7) are presented in Appendix. These coefficients are calculated for the tooth root with geometrical dimensions $h=13.0 \mathrm{~mm}, b=3.9 \mathrm{~mm}$ and $e=0.6$. Elastic properties of the PDL are assigned by constants $E_{\infty}=680$ $\mathrm{kPa}$ and $v=0.49$ (Tanne et al. 1991). Thickness $\delta$ of the PDL is $0.229 \mathrm{~mm}$ (Provatidis 2001). In this case, $a_{16}=$ $a_{61}=-44.168 \mathrm{kN}$ and $a_{34}=a_{43}=59.060 \mathrm{kN}$. Magnitudes of other coefficients of system (7) are given in Table 1.

Table 1 Coefficients of system (7)

\begin{tabular}{llllll}
\hline$a_{11}[\mathrm{M} \mathrm{N} / \mathrm{m}]$ & $a_{22}[\mathrm{M} \mathrm{N} / \mathrm{m}]$ & $a_{33}[\mathrm{M} \mathrm{N} / \mathrm{m}]$ & $a_{44}[\mathrm{~N} \cdot \mathrm{m}]$ & $a_{55}[\mathrm{~N} \cdot \mathrm{m}]$ & $a_{66}[\mathrm{~N} \cdot \mathrm{m}]$ \\
\hline 5.043 & 1.090 & 6.997 & 578.9 & 6.137 & 445.6
\end{tabular}


The coefficients $a_{i j}$ depend on the geometrical shape of the tooth root, the Poisson's ratio as well as the instantaneous and relaxed elastic moduli of the periodontal tissue and are time-independent. Therefore, they could be eliminated from the integrals in Eq. (7).

\section{Translational displacements of tooth root}

During the motion of the tooth root along the y-axis, corresponding to extrusion (or intrusion), the translational displacements along the $x$ - and $z$-axes, as well as the angles of rotation vanish, i.e., $u_{0 x}=u_{0 z}=0$ and $\theta_{x}=\theta_{y}=$ $\theta_{z}=0$; the load acts only along the $y$-axis. In this case, one obtains from (7)

$$
a_{22}\left(u_{0 y}-v_{\varepsilon} \int_{0}^{t} \mathcal{E}_{\gamma} u_{0 y}(t-\tau) d \tau\right)+M \frac{d^{2} u_{0 y}}{d t^{2}}=f_{y} .
$$

In the case of translational displacement of the tooth root in a horizontal plane, in particular, along the $x$-axis, $u_{0 y}=u_{0 z}=0$ and $\theta_{x}=\theta_{y}=\theta_{z}=0$. The load acts along the $x$-axis, and its line of action passes through the centre of resistance of the tooth root with coordinates $\left(0, y_{1}, 0\right)$. As a result, we have

$$
\begin{array}{r}
a_{11}\left(u_{0 x}-v_{\varepsilon} \int_{0}^{t} \mathcal{E}_{\gamma} u_{0 x}(t-\tau) d \tau\right)+M \frac{d^{2} u_{0 x}}{d t^{2}}=f_{x}, \\
a_{61}\left(u_{0 x}-v_{\varepsilon} \int_{0}^{t} \mathcal{E}_{\gamma} u_{0 x}(t-\tau) d \tau\right)=-y_{1} f_{x} .
\end{array}
$$

To obtain the system of equations describing the translational motion of the tooth root along the $z$-axis, it is necessary to equalize displacements $u_{0 x}$ and $u_{0 y}$ and all angles of rotation in (9) to zero. In this case, only the $z$-component of the load acts on the tooth, and its line of action passes through the centre of resistance with coordinates $\left(0, y_{2}, 0\right)$.

\section{Results}

\section{Strains in PDL during translational displacement of tooth} root

Physical parameters of the viscoelastic model can be assessed using Eq. 8, since stiffness $a_{22}$ of the PDL along the $y$-axis direction is smaller than $a_{11}$ and $a_{33}$. Duration of the load action on the tooth root is assumed to be large enough (from 0 to $300 \mathrm{~s}$, (Qian et al. 2009; Slomka et al. $2008)$ ), and the mass of the tooth root small $\left(m=1 \cdot 10^{-3}\right.$ $\mathrm{kg})$. Hence, the inertial term in Eq. (8) can be neglected:

$$
u_{0 y}-v_{\varepsilon} \int_{0}^{t} \mathcal{E}_{\gamma} u_{0 y}(t-\tau) d \tau=\frac{f_{y}}{a_{22}} .
$$

According to (Rossikhin 2010) solution of this equation can be written as

$$
u_{0 y}(t)=\frac{f_{y}}{a_{22}}\left(1+v_{\sigma} \frac{t^{\gamma}}{\tau_{\sigma}} \sum_{n=0}^{\infty} \frac{(-1)^{n}\left(\frac{t}{\tau_{\sigma}}\right)^{\gamma n}}{\Gamma[\gamma(n+1)]}\right),
$$

where $v_{\sigma}=\frac{E_{\infty}-E_{0}}{E_{0}}, \tau_{\sigma}$ is the retardation time. Solution (11) corresponds to the initial conditions $\left.u_{0 y}(t)\right|_{t=0}=\frac{f_{y}}{a_{22}}$ and $\left.\frac{d u_{0 y}(t)}{d t}\right|_{t=0}=\left.\frac{d^{2} u_{0 y}(t)}{d t^{2}}\right|_{t=0}=0$.

In Eq. ( 11$)$, stiffness $a_{22}$ is known (see Table 1), while the load $f_{y}$ must be specified. The retardation time $\tau_{\sigma}$, parameter $v_{\sigma}$ and fractional parameter $\gamma$ are unknown. The magnitudes of these parameters are assessed using the models for the tooth movement with time in the viscoelastic PDL that were analysed in (Qian et al. 2009; Slomka et al. 2008). The tooth displacement with time in the viscoelastic PDL was determined for a continuous load that changed from 0 to $15 \mathrm{~N}$ (Qian et al. 2009) as well as for a discrete change in the load magnitude from $0.5 \mathrm{~N}$ to $3.0 \mathrm{~N}$ with a step of $0.5 \mathrm{~N}$ (Slomka et al. 2008); the time intervals were $300 \mathrm{~s}$ (Qian et al. 2009) and $1200 \mathrm{~s}$ (Slomka et al. 2008). In our case, the calculation of displacements was performed for the time interval from 0 to $300 \mathrm{~s}$; the transition phase was 20-25 s (Qian et al. 2009; Slomka et al. 2008).

For a case of vertical loading of the tooth root, the highest strain in the PDL in the coordinate system $(n, t, \theta)$ was $\varepsilon_{n n}$ along the $y$-axis. Evolution of strains $\varepsilon_{n n}$ in the $x y$-plane for different points of the PDL on the surface of the tooth root is shown in Fig. 2. The tooth crown was loaded by a constant compressive force of $-2 \mathrm{~N}$, the fractional parameter $\gamma$ was equal to 0.35 ; the retardation time $\tau_{\gamma}$ and the parameter $v_{\sigma}$ were equal to $550 \mathrm{~s}$ and $1.3 \cdot 10^{3}$, respectively. The values of the above param-

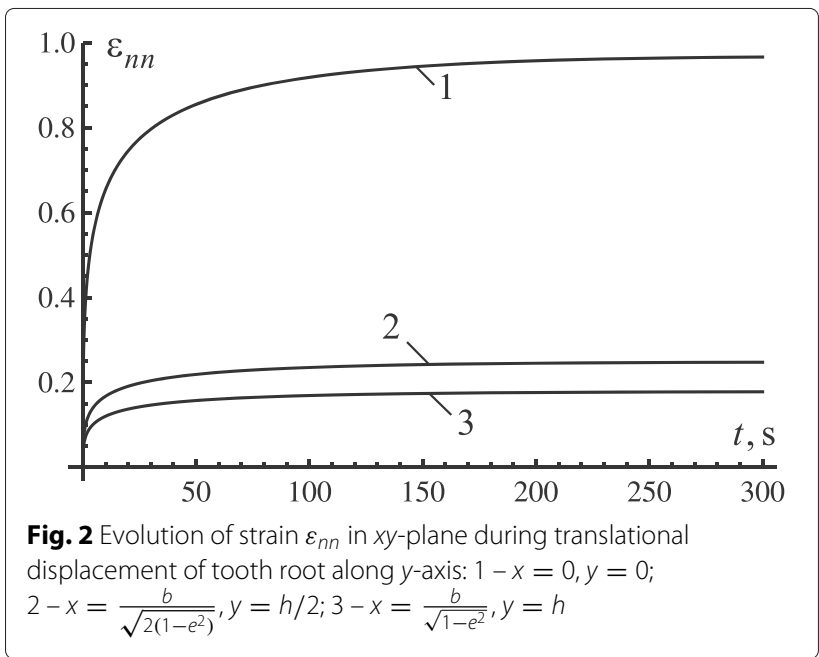


eters were determined from the condition $\varepsilon_{n n} \leq 1$ (in accordance with the first expression of relations (3)) for PDL's points located in the apex of the tooth root.

In addition to strain $\varepsilon_{n n}$, another nonzero strain is $\varepsilon_{n t}$. For the above magnitudes of load, geometric and physical parameters of the tooth root and the PDL as well as those of the fractional kernel, the absolute value of the strain does not exceed 0.45 for the first $300 \mathrm{~s}$.

The change of parameter $v_{\sigma}$ for different levels of the fractional parameter provided the same maximum displacements of the tooth root in the PDL. Figure 3 shows the change of displacements with time for the load of 2 $\mathrm{N}$ and retardation time of $550 \mathrm{~s}$. The choice of a combination of the constants $\gamma$ and $v_{\sigma}$ was based on the above condition $\varepsilon_{n n} \leq 1$, following from the first expression in (3).

Figures 2 and 3 demonstrate that a simultaneous change of the fractional parameter $\gamma$ and parameter $v_{\sigma}$ allows us to specify a necessary transitional phase and the maximum displacement of the tooth root in the PDL; this can be achieved for any load. The magnitude of the maximum strain can be defined by changing the magnitude of parameter $v_{\sigma}$, depending on the level of load.

According to results in Fig. 3, an increase of the fractional parameter leads to an increase in duration of the transition phase and in the level of the maximum displacement of the tooth root (for constant values of $v_{\sigma}$ and $\tau_{\sigma}$ ).

Evolution of the normal strains $\varepsilon_{n n}$ for the second particular case, corresponding to Eq. (9), are shown in Fig. 4 (the magnitudes of dimensions of the tooth root, constants of elasticity of the periodontal ligament remained the same). Since in this case the largest

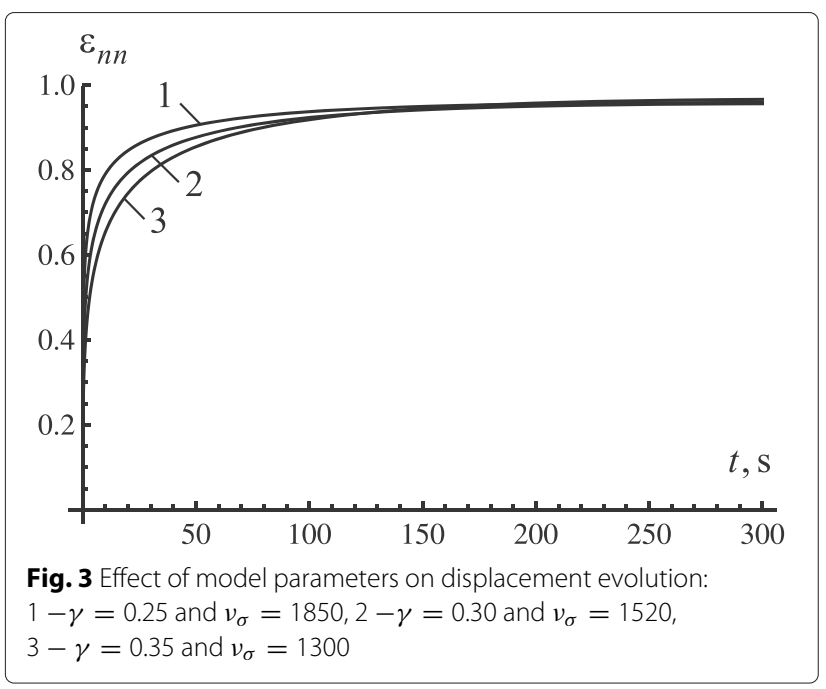

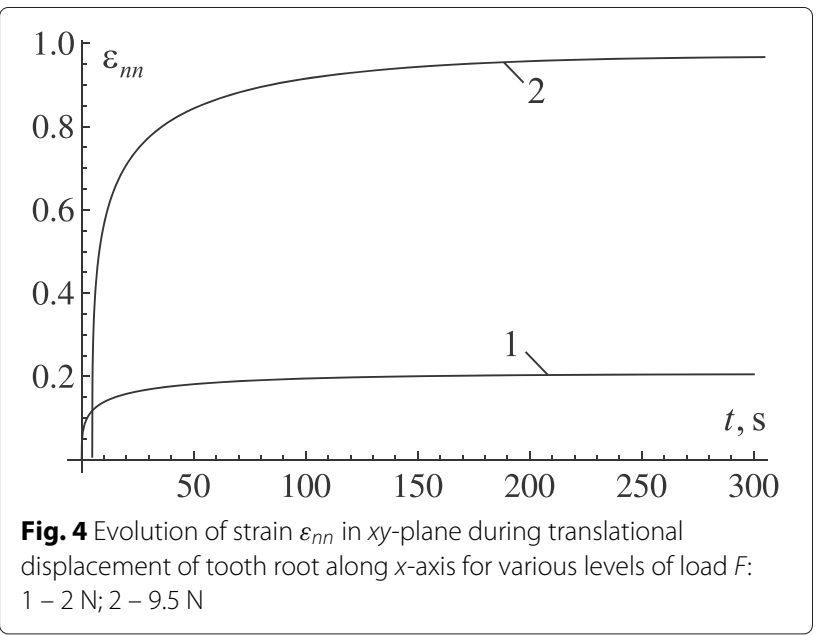

deformations occur near the alveolar crest, the deformations at the point with coordinates $\left(x=\frac{b}{\sqrt{1-e^{2}}}, 0, h\right)$ are defined. Parameters $\gamma, \tau_{\gamma}$ and $v_{\gamma}$ of the relaxation kernel are equal to $0.35,550 \mathrm{~s}$ and $1.3 \cdot 10^{3}$, respectively.

Figure 4 demonstrates that normal strains during the translational motions of the tooth root along the $x$ axis under the load of $2 \mathrm{~N}$ do not exceed 0.2. This can be explained by higher stiffness $a_{11}$ of the PDL compared with $a_{22}$. To displace the tooth root by distance $\delta$ along the normal to the surface in $x y$ plane, it is necessary to apply a force of some $9.5 \mathrm{~N}$ (Fig. 4).

\section{Hydrostatic stress of PDL}

As known, regions of the PDL exposed to highest hydrostatic stresses govern a bone-remodelling process during an orthodontic tooth movement (De Pauw et al. 2003; Middleton et al. 1996; Vollmer et al. 1999). Hydrostatic stress is determined as

$$
\sigma_{h}=\frac{1}{3}\left(\sigma_{x x}+\sigma_{y y}+\sigma_{z z}\right)
$$

As follows from (12) and the discussion above, the hydrostatic stress in the PDL during the translational displacement of the tooth root along the vertical axis is

$$
\sigma_{h}=\frac{E u_{0 y} \cos (\alpha)}{3 \delta(1-2 v)} .
$$

Diagrams of distribution of hydrostatic stresses on the tooth-root surface at various times are presented in Fig. 5 for the same magnitudes of load, geometric and physical parameters of the tooth root and the PDL.

Apparently (see Fig. 5), only areas in the close vicinity of the root's apex are characterised by hydrostatic 

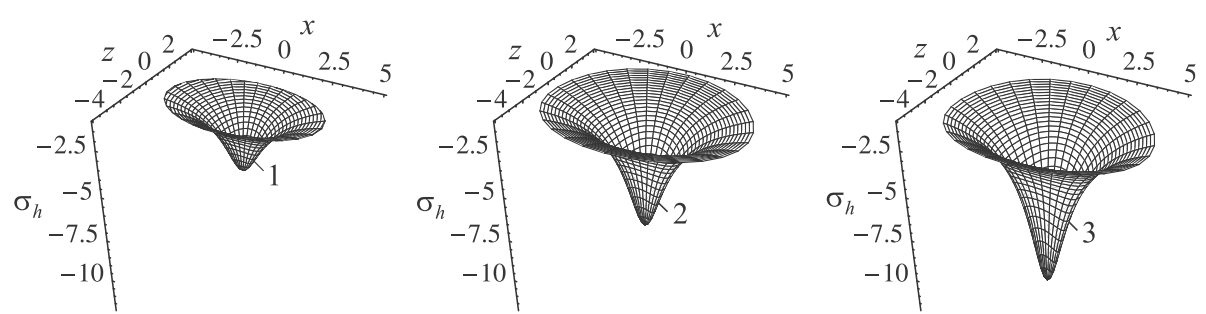

Fig. 5 Diagrams of hydrostatic stresses at different moments during translational displacement of tooth root along y-axis: $1-1 \mathrm{~s} ; 2-10 \mathrm{~s} ; 3-300 \mathrm{~s}$

stresses of considerable magnitudes. The highest stresses for the vertical displacement of the tooth root occur at its apex, while the lowest are observed near the alveolar crest. At $t=1 \mathrm{~s}$, the hydrostatic stress in the apical region is larger than that near the alveolar crest by approximately 14.1 times. With continuing load action, this ratio increases: at $t=10 \mathrm{~s}$ it is 14.25 , at $t=$ $300 \mathrm{~s}$ it is 14.4. A prolonged action of high hydrostatic stresses in the apical region of the tooth root can lead to bone resorption and detrimentally affect the patient. Note that bone resorption in the apical region during the tooth motion (including intrusion) was described in (Jeon et al. 1999; Mohandesan et al. 2007).

Stress distributions on the internal surface (1) of the PDL during the translational displacement of the tooth root along the $x$-axis under loads of $2 \mathrm{~N}$ and $9.5 \mathrm{~N}$ are shown in Fig. 6. The dimensions of the tooth root, elastic parameters of the PDL are the same, parameters $\gamma$, $\tau_{\gamma}$ and $v_{\gamma}$ of the relaxation kernel are equal to $0.35,550$ $\mathrm{s}$ and $1.3 \cdot 10^{3}$, respectively. In Fig. 6 , the coordinates $x$ and $z$ are in millimeters while the hydrostatic stress is in MPa. $a$
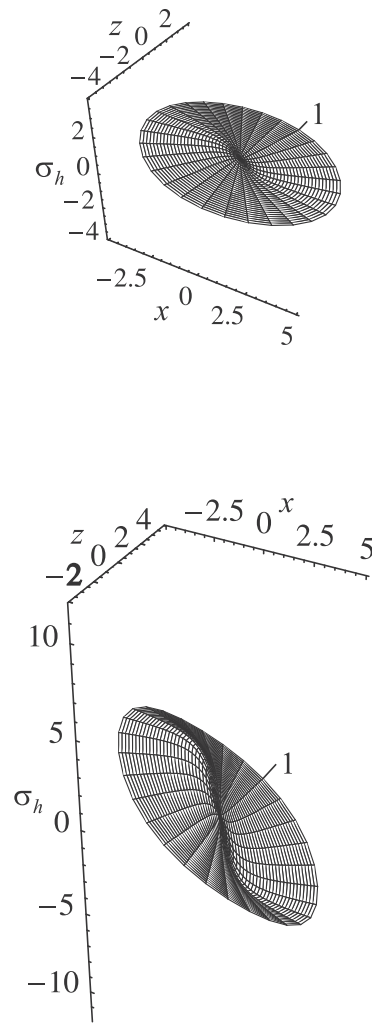

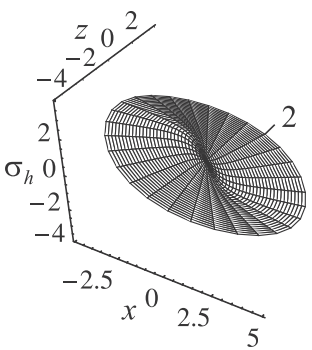

$b$
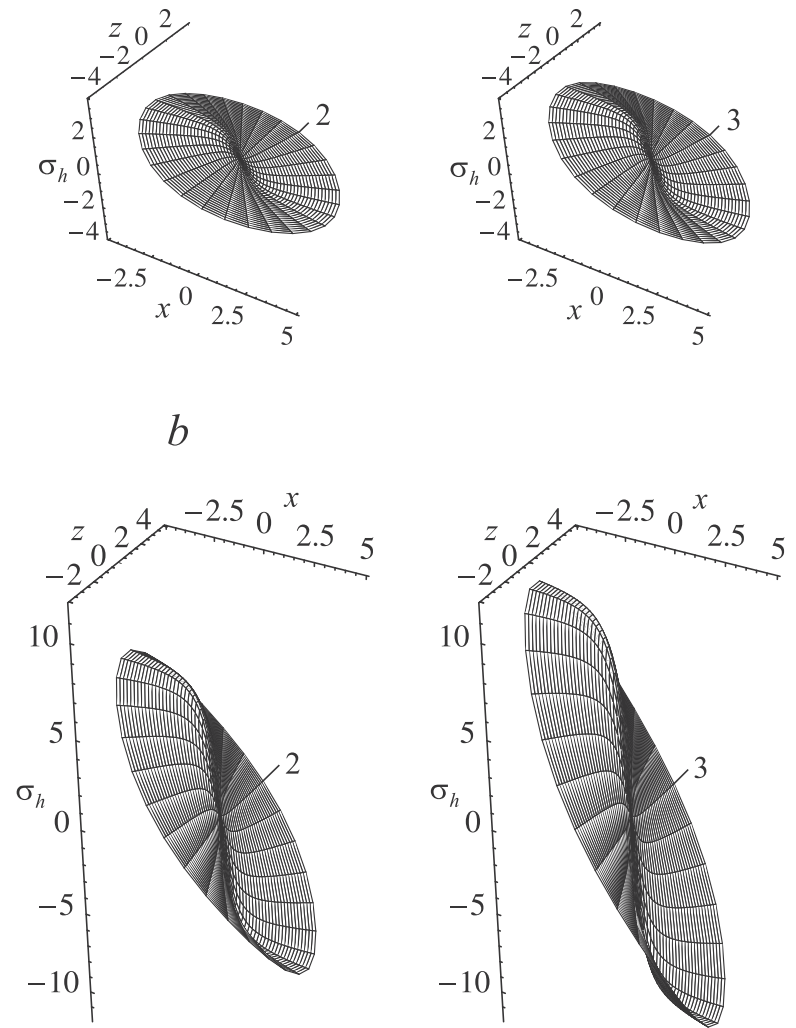

Fig. 6 Evolution of hydrostatic stresses with time during translational displacement of tooth root along $x$-axis under $2 \mathrm{~N}(\mathbf{a})$ and $9.5 \mathrm{~N}(\mathbf{b}): 1-1 \mathrm{~s}$; $2-10 s ; 3-300 s$ 
As seen in Fig. 6, the hydrostatic stress on a part of the internal surface of the PDL corresponding to $x>0$ are compressive; on the opposite side of the PDL the tension occurs. This indicates the bone-resorption process in the load direction and bone remodelling on the opposite side of the tooth root. The largest stresses are observed near the alveolar crest. At the point of the PDL corresponding to the apex of the tooth root the hydrostatic stresses vanish. However, in the apical region of the PDL, in particular at $x>0.9 \mathrm{~mm}$, the stresses reach sufficiently large values, comparable to those near the alveolar crest. Therefore, we can conclude that the outer contours of the hydrostatic-stress diagrams are limited by nearly straight portions (except for a small apical region). The bone remodelling would occur uniformly along the root surface during the translational displacement along the $x$ axis, while beneath the apex of the tooth root the bone would not change. An increase in the maximum hydrostatic stresses in the PDL with time during translational displacements of the tooth along the $y$-axis and $x$-axis occur in a similar way. The magnitude of maximum stress at $t=10 \mathrm{~s}$ and $t=300 \mathrm{~s}$ exceeds the respective value at $t=1 \mathrm{~s}$ by a factor of approximately 1.75 and 2.55 , respectively.

\section{Effect of series truncation}

A number of terms in the series of the approximate solution (11) affects substantially the calculated displacements of the tooth root with time. Especially significant is their impact at small values of the fractional parameter. In particular, when $\gamma=0.25$, the effect of the number of terms of a series becomes negligible for $n \geq 20$, for $\gamma=0.5$ this is achieved at $n \geq 10$, and for $\gamma=0.75$ at $n \geq 3$.

\section{Effect of inertia}

To assess the effect of inertia, presented by the term $M \frac{d^{2} u_{0 y}(t)}{d t^{2}}$ in solution (11), calculations were performed for the following ranges of parameters: retardation time between $350 \mathrm{~s}$ and $550 \mathrm{~s}$, the fractional parameter - from 0.25 to 0.90 , and parameter $v_{\sigma}-$ from $1.3 \cdot 10^{3}$ to $1.8 \cdot 10^{3}$. The tooth mass, as discussed, was $1 \cdot 10^{3} \mathrm{~kg}$, while the tooth-root dimensions and the elastic properties of the PDL were as above. The analysis indicated that in the time interval from 0 to $300 \mathrm{~s}$ the contribution of the inertial term was of the order of $10^{-11} \mathrm{~m} / \mathrm{s}^{2}$ to $10^{-10} \mathrm{~m} / \mathrm{s}^{2}$. Thus, the solution in the form of (11) can be used as a sufficiently good approximation of the vertical movement of the tooth root.

\section{Discussion}

The aim of this study is the development of a mathematical model for description of experimentally observed viscoelastic and time-dependent behaviours of the PDL. In particular, the analysis is focused on the evolution of translational displacements of the tooth root in the PDL under the vertical load (intrusion). The calculated tooth- root displacement with time at a constant load allowed comparing the behaviour of the viscoelastic model with the fractional exponential kernel with that of the known nonlinear viscoelastic model of the tooth-root movement developed in the studies (Qian et al. 2009; Slomka et al. 2008). The model was used to determine the level of hydrostatic stresses in the PDL under the constant intrusive load. The analysis showed that these stresses in the PDL remained practically constant along the surface of the tooth root, except for the region near the root apex. Hydrostatic stresses in this region were significantly higher, indicating potential bone resorption during the orthodontic motion.

\section{Conclusions}

The considered model employs the relaxation kernel with a fractional exponential function and is an extension of the linear scheme for an almost incompressible PDL (with the Poisson's ratio equal to 0.49), presented in studies (Provatidis 2001; Van Schepdael et al. 2013) it describes both the elastic and viscoelastic behaviours of the PDL. The current lack of experimental data on the time-dependent behaviour of the PDL under various loading conditions hinders development of adequate analytical approaches. One of the limitations of the suggested approach is the increase in the maximum displacement of the tooth with the increased load (similar to the behaviour of the model (Slomka et al. 2008)). At the same time, the proposed model allows generalization of the known analytical models of the viscoelastic PDL by introduction of the instantaneous and relaxed elastic moduli, as well as the fractional parameter. The advantage of this model is in the use of the fractional parameter $\gamma$ and the parameter $v_{\sigma}$ improving the description of various pathological processes and age-related changes in the PDL. The fractional parameter makes it possible to take into account different behaviours of the periodontal tissue under short- and long-term loads. For instance, it allows assessing the change in the time interval of a transition phase for a given maximum displacement. Another advantage of the phenomenological model proposed in this study is its capability to predict the behaviour of the PDL in conditions, not feasible in the experiment.

The developed approach can be applied to determine a magnitude of a load for orthodontic tooth movement corresponding to optimal stresses, as well as to simulate bone remodelling on the basis of changes of stresses and strains in the PDL during orthodontic movements. 


\section{Appendix}

The coefficients of system (7) has the following form:

$$
\begin{aligned}
& a_{11}=A \iint_{F}\left(b^{2}(1-2 v) \cos (\alpha)-2 h\left(2 H x\left(1-e^{2}\right)(1-v)+G z(1-2 v)\right) \sin (\alpha)\right) d F, \\
& a_{16}=a_{61}=-A \iint_{F}\left(\left(4\left(1-e^{2}\right) h v x^{2}+b^{2} y(1-2 v)\right) \cos (\alpha)+\right. \\
& \left.+\left(b^{2} H x(1-2 v)+2 h y\left(2 H x\left(1-e^{2}\right)(1-v)+G z(1-2 v)\right)\right) \sin (\alpha)\right) d F, \\
& a_{22}=A \iint_{F}\left(b^{2}(1-v) \cos (\alpha)+h(1-2 v)\left(H x\left(1-e^{2}\right)+G z\right) \sin (\alpha)\right) d F, \\
& a_{33}=A \iint_{F}\left(b^{2}(1-2 v) \cos (\alpha)+2 h\left(H x\left(1-e^{2}\right)(1-2 v)+2 G z(1-v) \sin (\alpha)\right) d F,\right. \\
& a_{34}=A \iint_{F}\left(\left(b^{2} y(1-2 v)+4 h v z^{2}\right) \cos (\alpha)+\right. \\
& \left.+\left(2 H h x y\left(1-e^{2}\right)(1-2 v)+G z\left(b^{2}(1-2 v)+4 h y(1-v)\right)\right) \sin (\alpha)\right) d F, \\
& a_{44}=A \iint_{F}\left(\left(2 h y z^{2}+b^{2}\left((1-2 v) y^{2}+2(1-v) z^{2}\right)\right) \cos (\alpha)+\right. \\
& \left.+\left(2 h H x\left(1-e^{2}\right)(1-2 v)\left(y^{2}+z^{2}\right)+G z\left(b^{2} y+2 h\left(2 y^{2}(1-v)+(1-2 v) z^{2}\right)\right)\right) \sin (\alpha)\right) d F, \\
& a_{55}=A \iint_{F}\left(b^{2}(1-2 v)\left(x^{2}+z^{2}\right) \cos (\alpha)+\right. \\
& \left.+2 h\left(G z\left(e^{2} x^{2}+(1-2 v)\left(x^{2}+z^{2}\right)\right)+H x\left(\left(x^{2}+z^{2}\right)(1-2 v)-e^{2}\left((1-2 v) x^{2}+2(1-v) z^{2}\right)\right)\right) \sin (\alpha)\right) d F, \\
& a_{66}=A \iint_{F}\left(\left(2 h x^{2} y\left(1-e^{2}\right)+b^{2}\left(2(1-v) x^{2}+(1-2 v) y^{2}\right)\right) \cos (\alpha)+\right. \\
& \left.+\left(b^{2} H x y+2 h\left(H x\left(1-e^{2}\right)\left((1-2 v) x^{2}+2(1-v) y^{2}\right)+G(1-2 v)\left(x^{2}+y^{2}\right) z\right)\right) \sin (\alpha)\right) d F, \\
& A=\frac{E_{\infty}}{2 \delta b^{2}(1+v)(1-2 v)}, H=\frac{x\left(1-e^{2}\right)}{\sqrt{\left(1-e^{2}\right)^{2} x^{2}+z^{2}}}, G=\frac{z}{\sqrt{\left(1-e^{2}\right)^{2} x^{2}+z^{2}}} .
\end{aligned}
$$

\section{Competing interests}

The authors declare that they have no competing interests.

\section{Authors' contributions}

All the authors contributed to preparation of the paper. All authors read and approved the final manuscript.

\section{Acknowledgements}

The authors acknowledge the support of FP7 IRSES Marie Curie grant No 610547 TAMER.

\section{Author details}

${ }^{1}$ Department of Mechanics and Mathematics, Belarusian State University, 4 Nezavisimosti Avenue, 220030 Minsk, Belarus. ${ }^{2}$ Department of Economics, Belarusian State University, 31, K. Marx, 22030 Minsk, Belarus. ${ }^{3}$ Institute of Mathematics, Physics and Computer Science, Department of Mathematics, Aberystwyth University, Penglais, SY23 3BZ Aberystwyth Ceredigion, UK.

${ }^{4}$ Wolfson School of Mechanical and Manufacturing Engineering Loughborough University, LE11 3TU Leicestershire, UK.

Received: 18 September 2015 Accepted: 20 October 2015 Published online: 16 November 2015

\section{References}

Bergomi M, Cugnoni J, Galli M, Botsis J, Belser UC, Wiskott HWA (2011) Hydro-mechanical coupling in the periodontal ligament: A porohyperelastic finite element model. J Biomech 44:34-38

Berkovitz BKB, Moxham BJ, Newman HN (1995) The periodontal ligament in health and disease. Mosby-Wolf, London

Bourauel C, Vollmer D, Jager A (2000) Application of bone remodeling theories in the simulation of orthodontic tooth movements. J Orofacial Orthoped 61:266-279

Burstone CJ, Pryputniewicz RJ, Bowley WW (1978) Holographic measurement of tooth mobility in three dimensions. J Periodont Res 13:283-294

Cattaneo PM, Dalstra M, Melsen B (2005) The finite element method: a tool to study orthodontic tooth movement. J Dent Res 84:428-433

Chatterjee K (2006) Periodontium. Jaypee Brothers Medical Publishers (P) Ltd New Delhi

Chiba M (2004) Mechanical properties of the periodontal ligament. Tsurumi Univ Dent J 30:201-213

Clement R, Schneider J, Brambs HJ, Wunderlich A, Geiger M, Sander FG (2004) Quasi-automatic 3D finite element model generation for individual single-rooted teeth and periodontal ligament. Comp Meth Prog Biomed 73:135-144

Davidovitch Z, Shanfeld JL (1975) Cyclic AMP levels in alveolar bone of orthodontically treated cats. Eur J Orthod 20:567-574 
Davidovitch Z, Finkelson MD, Stiegman S, Shanfeld JL, Montgomery PC, Korostoff E (1980) Electric currents, bone remodelling and orthodontic tooth movement. II. Increase in rate of tooth movement and periodontal cyclic nucleotide levels by combined farce and electric current. Am J Orthod 77:33-47

De Pauw G, Dermaut L, De Bruyn H (2003) The value of the centre of rotation in initial and longitudinal tooth and bone displacement. Eur J Orthod 25:285-291

Dorow C, Sander FG (2005) Development of a model for the simulation of orthodontic load on lower first premolars using the finite element method. J Orofacial Orthop 66:208-218

Dorow C, Krstin N, Sander FG (2003) Determination of the mechanical properties of the periodontal ligament in a uniaxial tensional experiment. J Orofacial Orthoped 64:100-107

Ferrari M, Sorrentino R, Zaronem F, Apicella D, Aversa R, Apicella A (2008) Non-linear viscoelastic finite element analysis of the effect of the length of glass fiber posts on the biomechanical behaviour of directly restored incisors and surrounding alveolar bone. Dent Mat J 27:485-498

Fill TS, Carey JP, Toogood RW (2011) Major PW. Critical review of current literature. J Dent Biomech, Experimentally determined mechanical properties of, and models for, the periodontal ligament. doi:4061/2011/312980

Fill TS, Toogood RW, Major PW, Carey JP (2012) Analytically determined mechanical properties of, and models for the periodontal ligament: Critical review of literature. J Biomech 45:9-16

Frost HM (1992) Perspectives: bone's mechanical usage windows. Bone Miner 19:257-271

Gorenflo R, Kilbas A, Mainardi F, Rogosin S (2014) Mittag-Leffler Functions, Related Topics and Applications. Springer-Verlag, Berlin

Haack DC, Haft EE (1972) An analysis of stresses in a model of the periodontal ligament. Int J Eng Sci 10:1093-1106

Hohmann A, Kober C, Young P, Dorow C, Geiger M, Boryor A, Sander FM, Sander C, Sander FG (2011) Influence of different modeling strategies for the periodontal ligament on finite element simulation results. Am J Orthod Dentofacial Orthop 139:775-783

Jeon PD, Turley PK, Moon HB, Ting K (1999) Analysis of stress in the periodontium of the maxillary first molar with a three-dimensional finite element model. Am J Orthod Dentofacial Orthop 115:267-274

Jones ML, Hickman J, Middleton J, Knox J, Volp C (2001) A validated finite element method study of orthodontic tooth movement in the human subject. J Orthod 28:29-38

Jonsdottir SH, Giesen EBW, Maltha JC (2006) Biomechanical behaviour of the periodontal ligament of the beagle dog during the first 5 hours of orthodontic force application. Eur J Orthod 28:547-552

Kawarizadeh A, Bourauel C, Jager A (2003) Experimental and numerical determination of initial tooth mobility and material properties of the periodontal ligament in rat molar specimens. Eur J Orthod 25:569-579

Koeller RC (1984) Application of fractional calculus to the theory of viscoelasticity. J Appl Mech 51:299-307. doi:10.1115/1.3167616

Koeller RC (2010) A theory relating creep and relaxation for linear materials with memory. J Appl Mech. doi:10.1115/1.4000415

Komatsu K (2010) Mechanical strength and viscoelastic response of the periodontal ligament in relation to structure. J Dent Biomech. doi:10.4061/2010/502318

Komatsu K, Sanctuary C, Shibata T, Shimada A, Botsis J (2007) Stress-relaxation and microscopic dynamics of rabbit periodontal ligament. J Biomech 40:634-644

Kusy RP, Tulloch JFC (1986) Analysis of moment/force ratios in the mechanics of tooth movement. Am J Orthod Dentofacial Orthop 90:127-131

Mainardi F (2010) Fractional Calculus and Waves in Linear Viscoelasticity. Imperial College Press and World Scientific, London

Masella RS, Meister M (2006) Current concepts in the biology of orthodontic tooth movement. Am J Orthod Dentofacial Orthop 129:458-468

Melsen B (2001) Tissue reaction to orthodontic tooth movement - a new paradigm. Eur J Orthod 23:671-681

Middleton J, Jones M, Wilson A (1996) The role of the periodontal ligament in bone modeling: The initial development of a time-dependent finite element model. Am J Orthod Dentofacial Orthop 109:155-162

Mohandesan H, Ravanmehr H, Valaei N (2007) A radiographic analysis of external apical root resorption of maxillary incisors during active orthodontic treatment. Eur J Orthod 29:134-139
Muhlemann HR, Zander HA (1954) Tooth mobility III. The mechanism of tooth mobility. J Periodont 25:128-137

Muraki H, Wakabayashi N, Park I, Ohyama T (2004) Finite element contact stress analysis of the RPD abutment tooth and periodontal ligament. J Dent 32:659-665

Nanci A, Ten Cate AR (2008) Periodontium. Mosby Elsevier, St. Louis

Natali AN (2003) Dental Biomechanics. Taylor and Francis, New-York

Natali AN, Pavan PG, Schrefler BA, Secchi S (2002) A multi-phase media formulation for biomechanical analysis of periodontal ligament. Meccanica 37:407-418

Natali AN, Pavan PG, Scarpa C (2004) Numerical analysis of tooth mobility: formulation of a non-linear constitutive law for the periodontal ligament. Dent Mat 20:623-629

Natali AN, Carniel EL, Pavan PG, Bourauel C, Ziegler A, Keilig L (2007) Biomechanical response of periodontal ligament of multi-rooted tooth. J Biomech 40:1701-1708

Natali AN, Pavan PG, Venturato C, Komatsu K (2011) Constitutive modeling of the non-linear visco-elasticity of the periodontal ligament. Comput Meth Prog Biomed 104:193-198

Naveh GRS, Chattah NLT, Zaslansky P, Shahar R, Weiner S (2012) Tooth-PDL-bone complex: Response to compressive loads encountered during mastication - A review. Arch Oral Biol 57:1575-1584

Nikolai RJ (1996) Rigid-body kinematics and single-tooth displacements. Am J Orthod Dentofacial Orthop 110:88-92

Nishihira M, Yamamoto K, Sato Y, Ishikawa H, Natali AN (2003) Mechanics of periodontal ligament. In: Natali AN (ed). Dental Biomechanics. Taylor and Francis, London

Pena E, Martinez MA, Calvo B, Doblare M (2007) An anisotropic visco-hyperelastic model for ligaments at finite strains. Formulation and computational aspects. Comp Meth Appl Mech Eng 44:760-778

Pena E, Pena JA, Doblare M (2008a) On modelling nonlinear viscoelastic effects in ligaments. J Biomech 41:2659-2666

Pena E, Martinez MA, Calvo B, Doblare M (2008b) Application of the natural element method to finite deformation inelastic problems in isotropic and fiber-reinforced biological soft tissues. Comp Meth Appl Mech Eng 197:1983-1996

Picton DCA (1990) Tooth mobility - an update. Eur J Orthod 12:109-115

Pietrzak G, Curnier A, Botsis J, Scherrer S, Wiskott A, Belser U (2002) A nonlinear elastic model of the periodontal ligament and its numerical calibration for the study of tooth mobility. Comp Meth Biomech Biomed Eng 5:91-100

Proffit WR, Fields HWJr, Ackerman JL, Sinclair PM, Thomas PM, Tulloch JFC (1993) Contemporary orthodontics. Mosby-Year Book Inc, Baltimore

Provatidis CG (2000) A comparative FEM-study of tooth mobility using isotropic and anisotropic models of the periodontal ligament. Med Eng Phys 22:359-370

Provatidis, C G (2001) An analytical model for stress analysis of a tooth in translation. Int J Eng Sci 39:1361-1381

Qian L, Todo M, Morita Y, Matsushita Y, Koyano K (2009) Deformation analysis of the periodontium considering the viscoelasticity of the periodontal ligament. Dent Mat 25:1285-1292

Rabotnov YN (1948) Equilibrium of an elastic medium with after-effect. J Appl Math Mech 12:53-62. doi:10.2478/s13540-014-0193-1

Rabotnov, Y N (1980) Elements of Hereditary Solid Mechanics. Mir Publishers, Moscow

Rees JS, Jacobsen PH (1997) Elastic modulus of the periodontal ligament Biomat 18:995-999

Reimann S, Keilig L, Jager A, Brosh T, Shpinko Y, Vardimon AD, Bourauel C (2009) Numerical and clinical study of the biomechanical behaviour of teeth under orthodontic loading using a headgear appliance. Med Eng Phys 31:539-546

Reitan K, Rygh P (1994) Biomechanical principles and reactions. In: Graber TM, Vanarsdall RL (eds). Orthodontics, current principles and techniques. CV Mosby Company, St Louis

Roberts WE, Chase DC (1981) Kinetics of cell proliferation and migration associated with orthodontically-induced osteogenesis. J Dent Res 60:174-181

Rogosin S, Mainardi F (2014) George William Scott Blair - the pioneer of fractional calculus in rheology. Comm Appl Ind Math. doi:10.1685/journal.caim.481

Ross GG, Lear CS, DeCou R (1976) Modeling the lateral movement of teeth. J Biomech 9:723-734 
Rossikhin YA (2010) Reflections on two parallel ways in the progress of fractional calculus in mechanics of solids. Appl Mech Rev 63:1-12. doi:10.1115/1.4000246

Rossikhin, Y, Shitikova MV (2013b) Nonlinear dynamic response of a fractionally damped suspension bridge subjected to small external force. Int J Mech 7:155-163

Rossikhin YA, Shitikova MV (2014) Centennial jubilee of academician Rabotnov and contemporary handling of his fractional operator. Frac Calc Appl Anal 17:674-683

Rossikhin YA, Shitikova, M V (2015) Centennial jubilee of academician Rabotnov and contemporary handling of his fractional operator. Frac Calc Appl Anal 17:674-683

Rossikhin YA, Shitikova MV, Popov II (2014) Dynamic response of a hereditarily elastic beam with Rabotnov's kernel impacted by an elastic rod. In: Proceedings of the 2014 International Conference on Mathematical Models and Methods in Applied Sciences, Saint Petersburg State Polytechnic University, Saint Petersburg, 25-31 September 2014

Slomka N, Vardimon AD, Gefen A, Pilo R, Bourauel C, Brosh T (2008) Time-related PDL: viscoelastic response during initial orthodontic tooth movement of a tooth with functioning interproximal contact - a mathematical model. J Biomech 41:1871-1877

Smith RJ, Burstone CJ (1984) Mechanics of tooth movement. Am J Orthod 85:294-307

Storey E (1973) The nature of tooth movement. Am J Orthod 63:292-314

Tanne K, Nagataki T, Inoue Y, Sakuda M, Burstone CJ (1991) Patterns of initial tooth displacement associated with various root lengths and alveolar bone heights. Am J Orthod Dentofacial Orthop 100:66-71

Toms SR, Eberhardt AW (2003) A nonlinear finite element analysis of the periodontal ligament under orthodontic tooth loading. Am J Orthod Dentofacial Orthop 123:657-665

Toms SR, Dakin GJ, Lemons JE, Eberhardt AW (2002) Quasi-linear viscoelastic behavior of the human periodontal ligament. J Biomech 35:1411-1415

Uchaikin W (2013) Fractional derivatives for physicists and engineers. Springer and Higher Education Press, Berlin and Beijing

Van Schepdael A, Geris L, Van der Sloten J (2013) Analytical determination of stress patterns in the periodontal ligament during orthodontic tooth movement. Med Eng Phys 35:403-410

Vollmer D, Bourauel C, Maier K, Jager A (1999) Determination of the center of resistance in an upper human canine and idealized tooth model. Eur J Orthod 21:633-648

West BJ, Bologna M, Grigolini P (2003) Physics of Fractal Operators. Springer-Verlag, New-York

Wise GE, King GJ (2008) Mechanisms of tooth eruption and orthodontic tooth movement. J Dent Res 87:414-434

Wood SA, Strait DS, Dumont ER, Ross CF, Grosse IR (2011) The effects of modeling simplifications on craniofacial finite element models: The alveoli (tooth sockets) and periodontal ligaments. J Biomech 44:1831-1838

Yoshida N, Koga Y, Peng CL, Tanaka E, Kobayashi K (2001) In vivo measurement of the elastic modulus of the human periodontal ligament. Med Eng Phys 23:567-572

Ziegler A, Keilig L, Kawarizadeh A, Jager A, Bourauel C (2005) Numerical simulation of the biomechanical behaviour of multi-rooted teeth. Eur J Orthodont 27:333-339

\section{Submit your manuscript to a SpringerOpen ${ }^{\circ}$ journal and benefit from:}

- Convenient online submission

- Rigorous peer review

- Immediate publication on acceptance

- Open access: articles freely available online

- High visibility within the field

- Retaining the copyright to your article

Submit your next manuscript at $\boldsymbol{\nabla}$ springeropen.com 